UDK 621.92

A.A. ZHOSAN, Ph.D. (Engineering), assoc. prof.

Krivoy Rog National University

\title{
THE METHOD OF SYNTHESIZING A NONPARMETRIC DISCRETE MODEL OF A BLACKBOX-TYPE DYNAMIC OBJECT WITH THE SCALAR INPUT AND OUTPUT
}

The work aims to present the results of elaborating an efficient method of synthesizing an equation of a dual discrete model and a regulator for a dynamic non-linear non-stationary blackbox-type object directly from the data of the real object state matrix measurements without conducting special experiments, calculating model coefficients or disrupting the normal technological process and with the training sequence of minimum length.

The methods used are based on the matrix theory, difference equations, Cramer's rule for the solution of systems of linear algebraic equations.

Scientific novelty. The work presents a novel demonstration that an expanded matrix of the controlled object state enables incorporating both the object model and the regulator and accomplishes principal concepts of dual control. Besides, Cramer's rule-based equations of a model enable assessing Lyapunov exponent signatures and therefore determining the current state of the controlled object pertaining to the attraction area or the repeller.

Practical relevance. During standard operation, parameters of technological objects often vary within a wide range as the objects are non-linear and/or non-stationary. Common present-day regulator methods are based on the assumption that controlled objects are linear and stationary. The assumption often leads to disturbances in the technological process control. The work develops and substantiates the approach based on the dual control concept enabling synthesis of regulators for linear, non-linear, non-stationary objects of control. There is no necessity of studying their physical nature, conducting special experiments to receive transient characteristics or transfer functions. The object is treated as a blackbox providing small sensitivity to external impacts and adaptation during normal performance.

Results. The work suggests the methods of synthesizing a regulator which can be presented both numerically and analytically. The regulator enables implementing the set output value applying modern controllers.

Keywords: blackbox, Cramer's rule, dual control, expanded matrix, Lagrange equations, Lyapunov exponent signature.

doi: 10.31721/2306-5451-2020-1-50-118-122

Problem and its connection with scientific and practical tasks. Successful solution of the task of controlling a dynamic object requires synthesizing its mathematical model. Though there are several ways of accomplishing the task, a number of problems arise as well.

Knowing physical principles of controlled object functioning, one can obtain corresponding differential or difference equations of the object model. For this, knowledge of the nature of the controlled model functioning is required in most cases. This holds true, even if Lagrange equations of the second kind are used.

When using the mathematical model in the form of differential equations, it is necessary to decide on the order, structure, form (linear, non-linear, steady-state, unsteady-state, etc.).

When accomplishing practical tasks, expressing laws of complex technological processes functioning in mathematical terms often appears problematic. For instance, sufficient accuracy is unachievable in describing material processing in a crusher or a mill, changes of the charge temperature in sintering considering hard controllable impacts of air flows caused by gas suction and complicated ways of air entries to the technological process chains is impossible. And these are only few of real disturbances.

For this reason, when synthesizing dynamic models of technological processes, it is often reasonable to choose vector functions of the right hand sides of differential equations of models from a set of polynomials which can be easily dealt with mathematically. However, physical adequacy of such models is doubtful and mathematical accuracy is only provided within the testing range. This requires frequent personnel interventions to adjust regulator performance.

Assigning test controlling actions, based on responses, coefficients of the right hand sides of model equations are chosen. The least squares method is a common technique for determining model coefficients, however it deteriorates correctness of the received result [1]. In other words, development of a global in time and state space model is hardly, if at all, possible.

Further work with the model of this type often needs linearity of equations. Here, two unfavourable factors should be noted: approximation of the vector of the right hand sides contains errors to which linearity errors are added. Another important problem is estimation of the discrete interval and

(c) Zhosan A.A., 2020 
model stability obtained in such a way. Neglect of the problem may cause bifurcations, attraction areas or repellers.

Analysis of studies and publications. The blackbox concept was formulated by W.R. Ashby in his work "An Introduction to Cybernetics" [2]. This idea is gaining popularity now and works with the known concept of dual control by A.A Feldbaum [3]. The concept suggests performing identification of a controlled object on each discrete interval, calculating a control action which is simultaneously a test one for identification of the object model on the next discrete interval.

Almost every encyclopedia in automatic control contains references to this work. However, to solve the problem, statistical methods are used which require a great number of test actions or operation data. This stereotypic approach (the more such data (training sequences) there are, the more accurate the result is) is erroneous as it requires observance of the superposition principle which can only be fulfilled in the ideal linear stationary object. Then the test sequence can be minimal and enables building a global model and not correcting it anymore. Such a trivial task is not dealt with in the present article. In case of a non-linear, non-stationary object, the test (training) sequence leads to the problem of data deterioration.

At present, many publications deal with creating regulators able to adapt to changes of the structure and parameters of controlled objects. Many of them are of equal relevance. So let us mention just some of them.

Problems of creating adaptive non-parametric regulators with dual properties are treated in [4]. However, it suggests using a linear apparatus to solve the problem. At that, data for the model are not directly from the object or in real time. The work states that "the weight function $v(t)$ as well as the variable $w(t)$ cannot be obtained from the object in the "input-output" direction. It is suggested to obtain the transition function $v(t)$ from the model in the "output-input", i.e. reverse, direction" ([4], $p$. 60) (hereinafter translation is ours). Besides, as is seen from the title of the article, the method is not expected to require parameter determination. At the same time, it is required to determine parameters of the bell function: " $\mathrm{H}$ ( ) is the bell (kernel) functions, cs is the blur parameter that satisfy certain convergence conditions ..." (ibid). The inverse operator determined by the transition function (the linear concept again) is used. The approach like that to non-stationary non-linear object control seems rather cumbersome. Obtaining the transition function is not allowed at every object. Certainly, works of this kind are a step forward towards elimination of the necessity to know the exact structure of the controlled object model and physics of its parameters. Nadaraya methods apply indirect parameters. However, cumbersomeness of such approaches is obvious.

Implicit methods of dual control through mathematical approximation of Bellman stochastic dynamic programming equations are considered in [5]. The applied mathematical tools are rather complex and cumbersome for engineers.

The model in the form of an extended matrix of the controlled object state and the algorithm of its processing suggested in [6] was then developed. The basic feature of the approach is waiver of building a global model of the controlled object using large data bulk. In case of non-stationary objects, old data are a bottleneck. There were conducted multiple numerical experiments with objects swapping steady and non-steady states, (swapping the attraction area and the repeller), the model of a vertical pendulum with the low pivot [7,8] and the physical model of a heating furnace. Besides, the methods considered in this work were used to predict the state of the model of the technological process of ore material disintegration [9] and confirmed by real performance data.

In his previous works, the author describes application of the mentioned approach with various algorithms of processing the extended matrix but he does not provide any rigorous proof of the method.

In the present work, the author presents only one of his arguments of fidelity of using the extended state matrix as a blackbox model.

Problem statement. The task of the work is to prove that an extended state matrix is a basis for forming a discrete dual model of a non-linear non-stationary dynamic controlled object.

Material Presentation and Results. Let us consider principal statements of the blackbox model synthesizing method through the example of a non-linear non-stationary discrete object with the scalar input and output in the form of the difference equation

$$
x[n+1]=a(n, x[n-1], u[n-1]) x[n]+b(n, x[n-1, u[n-1]) u[n],
$$


where $n$ is a number of the discrete time interval; $\mathrm{x}[n]$ is the output response of the object; $u[n]$ is a control action; $a(n, x[n-1], u[n-1]), b(n, x[n-1], u[n-1])$ are coefficients - functions of the discrete time and the output response of the object and the control action. It is quite clear that the coefficients can be determined not later than on the [n-1]-th interval. Below, these coefficients are designated as $a$ and $b$ without simplification of their meaning. Considering the above, the object movement equation takes the following form

$$
x[n+1]=a x[n]+b u[n] .
$$

The object parameters including the discrete interval are assumed to be unknown. More detailed treatment of the discrete interval is presented in analysis of the obtained results. The output response and the input action (control) calculated by the regulator can be measured. This is a typical case of a blackbox. Control actions u[*] at the initial stage of putting the object into operation are assigned within the tolerance region and then calculated by the regulator during its operation (considered later on in the present article). From this point onward the sign "*" means "for any discrete time moment" or when it is seen from the context. This symbol attracts more attention than, for instance, $u[]$.

Let us compose equations concerning two unknown coefficients $a$ and $b$ of model (1) on the discrete time interval: $[\mathrm{n}],[\mathrm{n}-1],[\mathrm{n}-2]$

$$
\begin{aligned}
& x[n]=a x[n-1]+b u[n-1], \\
& x[n-1]=a x[n-2]+b u[n-2] .
\end{aligned}
$$

Let us use Cramer's rule to determine coefficients of model (2)

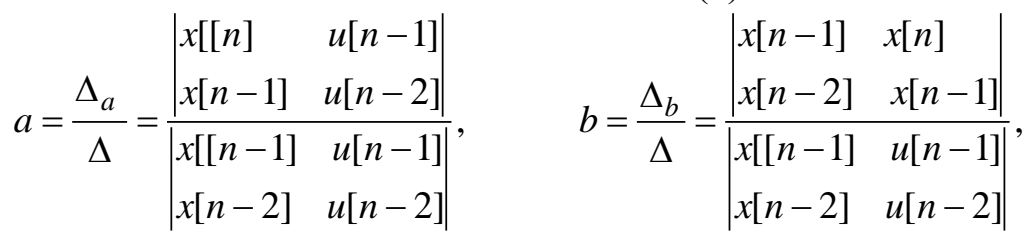

where $\Delta, \Delta_{\mathrm{a}}, \Delta_{\mathrm{b}}$ are determinants of system (2).

Let us present equation (1) in the equivalent form

$$
x[n+1]-a x[n]-b u[n]=0 .
$$

Then, considering (3), the equation of model (1) is obtained in the following form

$$
x[n+1]\left|\begin{array}{ll}
x[[n-1] & u[n-1] \\
x[n-2] & u[n-2]
\end{array}\right|-\left|\begin{array}{ll}
x[[n] & u[n-1] \\
x[n-1] & u[n-2]
\end{array}\right| x[n]-\left|\begin{array}{lc}
x[n-1] & x[n] \\
x[n-2] & x[n-1]
\end{array}\right| u[n]=0 .
$$

This is the desired difference equation of the blackbox-type model where only measured output data and the regulator-calculated control action are used. Model (4) does not contain coefficients of the controlled object, at least in the obvious form. The model is almost continuously adapting to changes of the controlled objects. The "input-output" data are continuously arriving for processing. The impression that the model does not consider parametric and structural as well as external disturbances unavailable for measurement is not quite true. The fact is that the mentioned disturbances inevitably impact the output data $x\left[{ }^{*}\right]$. Numerical and field tests of models of such disturbed object demonstrate positive results.

It should be noted that model (4) enables assessing Lyapunov exponent signatures and therefore determining the current state of the controlled object as pertaining to the attraction area or the repeller.

The purpose of further investigation within the framework of the present work is to find another, perhaps easier and more practical, algorithm of synthesizing models of the form of (4).

Let us build the extended object state matrix that includes measurable values of the output $x\left[{ }^{*}\right]$ as well as calculated and implemented values of control $u\left[{ }^{*}\right]$ at discrete moments of time $[\mathrm{n}+1],[\mathrm{n}]$, [n-1], [n-2]

$$
M(X, U)=\left(\begin{array}{lll}
x[n+1] & x[n] & u[n] \\
x[n] & x[n-1] & u[n-1] \\
x[n-1] & x[n-2] & u[n-2]
\end{array}\right),
$$

where $X, U$ are vectors-columns of output and control respectively. 
There occurs the following theorem: $\operatorname{det}(\mathrm{X}, \mathrm{U})=0$ is the difference equation of a controlled object of the form of (4).

Proof of theorem.

Let us develop the determinant of matrix (5) by the leftmost column and equate it to zero

$$
x[n+1]\left|\begin{array}{ll}
x[[n-1] & u[n-1] \\
x[n-2] & u[n-2]
\end{array}\right|-\left|\begin{array}{ll}
x[[n] & u[n-1] \\
x[n-1] & u[n-2]
\end{array}\right| x[n]+\left|\begin{array}{ll}
x[n] & x[n-1] \\
x[n-1] & x[n-2]
\end{array}\right| u[n]=0 .
$$

Comparison with (4) shows that after permutation of the columns in the last determinant the obtained expression completely coincides with the equation of the difference blackbox model (4). The theorem is proved.

Earlier, model (4) was successfully used in numerical simulations of various objects the state of which was changing from stable to instable. Besides, there were conducted tests on the physical model of a heating furnace as well as in the prediction mode on the basis of real data on ore raw material disintegration processes [9]. The present work provides theoretical substantiation of the methods.

Conclusions and directions for further research. Obtained model (5) is built on the latest data measured on the basis of operation results and represents a predictor enabling determining the output value $x[n+1]$ by the set input value $u[n]$. The required control action $u[n]$ can be easily obtained from the same expression at the assigned value of output $x[n+1]$ without matrix reversion. In this case, the expression becomes an analytical regulator. External disturbances impact output data and in this way are considered in calculating the control action.

The mentioned approach fully corresponds to the concept of dual control: the predicator or regulator models are updated on each interval.

The author's further research aims to develop regulator synthesis methods for multi-connected systems, i.e. systems with the vector input and output, assess Lyapunov exponent signatures of the object movement process and therefore determine its current state as pertaining to this or that kind of attractor [10], this being significant for practical application.

\section{References}

1. Лнейная алгебра и ее применения / Г. Стренг; Перевод с англ. Ю. А. Кузнецова, Д. М. Фаге. - М. : Мир, 1980. - 454 с. : ил.; 22 см.; ISBN В пер. (В пер.): Перевод изд.: Linear algebra and its applications / Gilbert Strang (New York etc., 1976).

2. Эшби У.Р. Введение в кибернетику. Под редакцией В. А. УСПЕНСКОГО - М.: Издательство иностранной литературы, 1959, с 128-129.

3. Fel'dbaum, A., 'Dual control theory I-IV', Automat. Remote Control, 21, 874-880,1033-1039 (1960); 22, 1-12, 109121 (1961).

4. А. В. Медведев.Теория непараметрических систем. управление-І Сибирский государственный аэрокосмический университет имени академика М. Ф. Решетнева, Россия, 660014, Красноярск, просп. им. газ. "Красноярский рабочий", 31. E-mail: Saor_medvedev@sibsau.ru, c. 57-63.

5. D. S. Bayard and A. Schumitzky. Implicit dual control based on particle filtering and forward dynamic programming. International Journal of Adaptive Control and Signal Processing, 24(3):155-177, 2010.

6. Жосан А.А. Разработка алгоритмов дуального управления центробежным дезинтегратором руд.: Дисс. на соискание степени канд. техн. наук по спец. 05.13.07, Кривой Рог, Криворожский технический университет, 1998, $-119 \mathrm{c}$.

7. Жосан А.А. Особенности управления процессом дезинтеграции твердых материалов как "черным ящиком" с бифуркационной точкой. Міжнародна науково-технічна конференція Розвиток промисловості та суспільства. Матеріали конференції. Кривий Ріг - 2018. том 2,С.148.

8. Жосан А.А. Федоренко О.Л. Дуальне управління перевернутим маятником як “чорним ящиком”. Вісник Криворізького національного університету.Збірник наукових праць. Випуск 44, 2017. С. 24-29.

9. Anatoliy Zhosan, Sergey Lipanchikov. Numerical modeling of disintegration process dual control Metallurgical and Mining Industry 2015, No. 3, p.p 74-77.

10.Takens F. Detecting strange attractors in turbulence // Lec. Notes in Math., 1981.V. 898. P. 366-381.

The editorial board received a manuscript on 02.04 .2020 